\title{
Considerations of a horizontal axis tidal turbine
}

T. O'Doherty PhD, CEng, FIMechE, MEl, A. Mason-Jones PhD, D. M. O'Doherty PhD, CEng, FIMechE, MEl,

P. S. Evans MSc, C. F. Wooldridge PhD, FRICS, IMarEST and I. Fryett PgDip., BSc, FHEA,

This paper considers the performance of a horizontal axis tidal turbine, at two sites off the Welsh coast of the UK, one in the Severn estuary and the second off Anglesey. Acoustic Doppler current profiler surveys were performed to investigate local velocity profiles. A small water plane area twin hull (Swath) bathymetric survey established the local bathymetry of the area. Energy extraction from a threebladed $10 \mathrm{~m}$ diameter turbine was studied using a quasistatic computational fluid dynamics model and velocity profile data from the acoustic Doppler current profiler surveys. The acoustic Doppler current profiler data were rescaled allowing further insight to the attenuation of power density through the water column at a higher tidal velocity. The velocity profile has a significant effect on power attenuation reducing the extracted power to $30-40 \%$ of peak power. The turbine performance calculation is highly dependent on the velocity used; the velocity should be monitored around five turbine diameters upstream, at the depth of its axis of rotation. The axial load on the turbine peaks at the freewheeling velocity dropping to $88 \%$ at peak power. It is suggested that the velocity at the Severn estuary site is, unlike the Anglesey site, unlikely to provide a suitable level of power to be viable.

\section{NOTATION}

A swept area $\left(\mathrm{m}^{2}\right)$

$C$ speed of sound $(\mathrm{m} / \mathrm{s})$

$C_{\mathrm{p}} \quad$ power coefficient

$C_{\mathrm{T}} \quad$ axial thrust coefficient

$F_{\mathrm{D}}$ change in the received frequency at the receiver (i.e. the Doppler shift) (Hz)

$F_{\mathrm{s}} \quad$ frequency of the transmitted sound (Hz)

$\boldsymbol{F}_{\mathrm{t}} \quad$ axial thrust $(\mathrm{N})$

$P \quad$ power $(\mathrm{W})$

$P_{\mathrm{p}} \quad$ peak power $(\mathrm{W})$

$\boldsymbol{T}$ torque $(\mathrm{Nm})$

$\boldsymbol{V} \quad$ velocity $(\mathrm{m} / \mathrm{s})$

$\boldsymbol{V}_{\mathrm{R}}$ relative velocity of particles between source and receiver $(\mathrm{m} / \mathrm{s})$

$\rho \quad$ density $\left(\mathrm{kg} / \mathrm{m}^{3}\right)$

$\boldsymbol{\omega} \quad$ angular velocity $(\mathrm{rad} / \mathrm{s})$

\section{INTRODUCTION}

Tidal energy can provide a highly predictable and sustainable level of energy that is dependent on the tidal cycle. The emerging technologies for tidal energy generation provide two very different approaches: impoundment schemes, such as barrages and lagoons, or schemes that directly utilise the tidal current - that is, tidal stream turbines. Tidal stream turbines can be fully submerged below the water level and thus do not provide a visual obstruction to the landscape, although they may have an impact on the local marine environment. They can be seabed mounted, for example by way of a pile-driven stanchion, or floated at a desired depth through the water column. There are a number of devices currently under development that fall into a number of categories. The main types are horizontal or vertical axis turbines, although other designs are venturi devices that can be used to concentrate the flow and oscillating hydrofoils that move up and down through the water column, generating electricity by way of the pumping of hydraulic fluids. Unlike the impoundment schemes, tidal stream turbines allow the water to pass through and around them and do not require water to be stored.

Much of the technology associated with horizontal axis tidal turbines (HATTs) is derived from the wind industry; however, the environment in which they operate produces higher structural loading with the addition of biological fouling from marine life, possible interaction with the free surface, increased material corrosion from salts and the possibility of blade cavitation at shallower water depths. As a result the design criterion for a HATT requires a high degree of robustness with a limited maintenance schedule to reduce both operational cost and embodied carbon dioxide emissions (Douglas et al., 2007).

Of the $382.5 \mathrm{TWh} /$ year of electricity demand in the UK (Sustainable Development Commission, 2007a), tidal stream resources have the potential to generate $15.6 \mathrm{TWh} /$ year or approximately $4 \%$ of the UK electricity demand (Black \& Veatch, 2005). However, this figure is slightly reduced by the 'significant impact factor' (SIF), which is defined as 'the percentage of the total resource that can be extracted without significant economic or environmental effect, to give the available resource' (Black \& Veatch, 2005). The resulting figure of $12 \mathrm{TWh} /$ year represents the UK tidal stream resource that could be economically exploited if the technology were to be fully developed and deployed.

To date UK tidal stream technology has resulted in a number of installed full-scale devices. Marine Current Turbines (MCT) 
introduced the world's first offshore tidal stream turbine, the $11 \mathrm{~m}$ diameter twin-bladed Seaflow, which was built into the seabed $1.5 \mathrm{~km}$ offshore from Lynmouth, Devon. It is capable of producing $300 \mathrm{~kW}$ of electricity at a tidal flow of approximately $2 \cdot 8 \mathrm{~m} / \mathrm{s}$ ( $5 \cdot 5 \mathrm{knots}$ ) (DTI, 2006). MCT has also developed the more recent $1 \cdot 2 \mathrm{MW}$ SeaGen project at Strangford Lough off the coast of Northern Island. This should supply up to 1000 homes with electricity (Sustainable Development Commission, 2007a). MCT has also commenced studies for a small array of seven turbines in the Skerries off Anglesey (Marine Current Turbines, 2009).

Resulting from recommendations made by the House of Commons science and technology select committee in 2001 the European Marine Energy Centre (EMEC) with its five tidal stream test sites was established. EMEC is situated $2 \mathrm{~km}$ offshore at the Fall of Warness, off Eday, Orkney and is fast becoming a major centre for the testing of tidal stream and wave devices (EMEC, 2008; Sustainable Development Commission, 2007a). The Dublin-based OpenHydro Group Ltd has installed a $250 \mathrm{~kW}$ prototype open-centre turbine at the site as part of its plans to develop a deep sea application (Sustainable Development Commission, 2007b).

The clear advantage of tidal stream turbines is that they can be sized to suit the requirements of the local environment - that is, coastal restrictions, tidal flow, tidal range, seabed topography and so on - and can be placed on either an individual or 'farm' configuration. As such, no large civil works are required and this method would therefore be less disruptive to wildlife, marine activity (and possibly the coastline) and would not present a significant barrier to water transport. A recent study in the Strangford Loch has shown that there were no effects on the wildlife and environment following the installation of the SeaGen turbine within those waters (Green Party, 2009), although the study is ongoing (Savage, 2009). It has been stated that the ideal site for a tidal stream turbine is within $1 \mathrm{~km}$ of the shoreline and at a depth of 20 to $30 \mathrm{~m}$ (Fujita Research, 2000). The ideal tidal speed is 2 to $3 \mathrm{~m} / \mathrm{s}$ (between approx. 4 and 6 knots) as higher speeds can lead to blade-loading problems (Soares, 2002).

A multidisciplinary research programme in tidal stream energy was undertaken between Cardiff University's schools of engineering and earth, ocean and planetary sciences, and Swansea University's schools of engineering and environment and society. This paper considers aspects of the hydrographic and hydrodynamic part of the study. A high-resolution small water plane area twin hull (Swath) bathymetric survey and a series of vessel-mounted acoustic Doppler current profiler (ADCP) surveys were undertaken in order to investigate the feasibility of installing a HATT off the Welsh coast. The bathymetric survey provided accurate and detailed bathymetry of the sites, thus facilitating the identification of suitable areas to site a HATT, in terms of a relatively deep flat location.

The ADCP transect surveys were performed to investigate the current velocities through the water column in order to become acquainted with the overall flow regime. Flow velocities, principally the mean speed for a given direction, were measured in order to assess whether the currents possess the necessary strength to power the HATT and thus determine the characteristics of the turbine; that is, power, torque and so on.
This paper examines the Swath and ADCP data from two sites: one in the Severn estuary and the second within the Anglesey Skerries and uses the data as part of computational fluid dynamic (CFD) models of a $10 \mathrm{~m}$ diameter HATT at each of these locations. This enables the power, torque and axial loading characteristics of the turbine to be determined at each of these sites. The paper not only considers the two sites for their feasibility for siting tidal stream turbines but also examines the severity of velocity profiles. In addition the profiles with the peak velocities were scaled to be the same depth and to have a peak velocity equal to that required to be economically viable. With the position of the turbine fixed in a vertical position to allow shipping to pass over the blades a comparison has been made in the turbine's performance, where only the velocity profile, hence shear, is the variable.

\section{FIELD SURVEY}

A field survey of the Welsh coastline was undertaken with the aim of identifying two sites that were suitable for a $10 \mathrm{~m}$ diameter HATT. Velocity profiles were also determined at the sites during part of the tidal cycle. Suitability was judged in terms of the seabed topography, as identified by the Swath bathymetry measurements, and the tidal velocities obtained from the ADCP data.

Initially, a review of the Admiralty charts for the Welsh coast identified two potential areas that would be suitable for the siting of one or more HATTs. The first was within the Severn estuary and was located approximately 3 nautical miles south of Stout Point, South Wales (latitude 51.331, longitude 3.395) in water depths varying from approximately -18 to $-35 \mathrm{mCD}$. The second was within the Anglesey Skerries (latitude 53.415, longitude -4.584 ) with water depths varying between -25 to $-37 \mathrm{mCD}$. The water depth is defined in relation to chart datum such that a depth of $0 \mathrm{mCD}$ is the depth at the lowest astronomical tide (LAT).

\section{I Swath bathymetry measurements}

The Swath bathymetry system was utilised to collect highresolution depth data $(0 \cdot 1 \mathrm{~m}$ accuracy) over the pre-designated $1 \mathrm{~km}^{2}$ survey location by running eight transects, spaced at $130 \mathrm{~m}$, across the survey area in an alternating direction. The Swath system is side mounted beneath the hull of the boat and emits a sonar signal which is composed of numerous straight beams which are reverberated back from the seafloor beam. By measuring the time interval between the emission and reception of the signal and knowing the exact position of the boat (using a global positioning system (GPS)), the depth and sonar reflectivity of the seabed within the beam angle can be determined. As the survey vessel moved forwards, the profiles combined to form a Swath of depths across the survey area. By measuring the motion and location of the transducers using ancillary devices, the depth information was correctly located with respect to the Earth's surface.

The bathymetric data were used to identify relatively deep flat seabed areas which may be suitable for a HATT. In order to match the specifications outlined in the Carbon Trust report, Variability of UK Marine Resources (Carbon Trust, 2005), a $10 \mathrm{~m}$ diameter turbine needed to be considered for each site. Deep areas were chosen to ensure that there was sufficient depth for a $10 \mathrm{~m}$ diameter turbine and clearance for any shipping passing 
through the site. Positions in the Severn estuary and the Anglesey location were chosen and the velocity profiles at these sites were then investigated using ADCP. It should be noted that owing to limited depths above certain banks it is expected that vessels of a draft up to $14.5 \mathrm{~m}$ may deem it a safe route, particularly in the Severn estuary. Therefore, for this study a maximum draft of $15 \mathrm{~m}$ was assumed in the vicinity of the turbine.

\subsection{ADCP data}

A hull-mounted ADCP was used to estimate the horizontal and vertical velocity as a function of depth by using the Doppler effect to measure the radial relative velocity between the instrument and that scattered in the ocean. As a minimal requirement for measuring the three velocity components, the study used three acoustic beams in different directions (east, north and up directions) to generate sound pulses at a given frequency (in this case $1 \mathrm{MHz}$ ) along a narrow beam of sound, in which the energy is concentrated in a cone approximately $2^{\circ}$ wide. As the sound propagates through the water column, it is reflected in all directions by particulate matter, specifically sediment, biological matter and bubbles, but a certain amount of the reflected energy travels back along the transducer axis towards the transducer where the processing electronics measure the backscattered frequency, and thus the Doppler shift. The Doppler shift states that if a source of sound is moving relative to the receiver, the frequency of the sound at the receiver is shifted from the transmit frequency given by

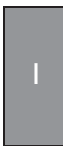

$$
F_{\mathrm{D}}=2 F_{\mathrm{s}}\left(\frac{\boldsymbol{V}_{\mathrm{R}}}{C}\right)
$$

The frequency increases if the distance between the transducer and the reflecting object is decreasing but decreases if the distance is increasing. The Doppler shift measured by a single transducer thus quantifies the mean velocity of the water along the axis of the acoustic beam (Kostaschuk et al., 2005).

Owing to various logistical difficulties, the ADCP data at the Severn estuary site were collected during the spring ebb tide, while the data for the four sites in the Anglesey Skerries were collected during the neap tide. At each location the current velocities were measured by running fourteen $1 \mathrm{~km}$ transect lines perpendicular to the mean tidal flow using an ADCP. Each transect took approximately $30 \mathrm{~min}$ to complete and provided mean velocity data for the entire water column. Depending on the water depth, between 19 and 26 data points were taken through the water column at $5 \mathrm{~s}$ intervals along the transect line. Routine processing, quality control, and calibration were performed which included detecting and correcting time errors, applying transducer-level temperatures and salinities to obtain a better estimate of the sound speed for the velocity calculation. In addition data that were contaminated by interference with the bottom or some other physical object were edited out. Although data were collected at the four sites identified within the Anglesey location, only the data obtained at site 2 are presented in this paper. This site was chosen because it was deemed as representative of the four positions and provided the flattest section of the seabed. It will henceforth be referred to as the Anglesey site.

\subsubsection{Velocity data sets. The averaged filtered current} velocities, for the Severn estuary, over the spring ebb tidal cycle, are shown in Figure 1, where the first data point in each data set (e.g. HWS +2 ) corresponds to the velocity at the surface. A number of points in the tidal cycle were detailed and are shown for the times corresponding to high water spring (HSW) $+n$ hours; for example, HWS +2 , HWS +3 and HWS +6 referenced to the water depth. The different depths for the first data point in each data set reflect the fact that the tide was falling.

If a $10 \mathrm{~m}$ diameter HATT was to be sited in these waters such that shipping could safely pass over it, it would need to be placed such that the axis of rotation of the turbine was $10 \mathrm{~m}$ from the seabed, assuming the largest shipping draft was $15 \mathrm{~m}$ and leaving adequate freeboard at all times.

Considering the conditions at HWS +2 , it can be seen from Figure 1 that with the $10 \mathrm{~m}$ diameter HATT positioned $10 \mathrm{~m}$ from the seabed, there would be a velocity shear of $0.82 \mathrm{~m} / \mathrm{s}$ within the depth bounded area of the HATT since the velocity at a depth of $-20 \mathrm{mCD}(25.6 \mathrm{~m})$ is $1.21 \mathrm{~m} / \mathrm{s}$ and the velocity at a depth of $-30 \mathrm{mCD}(35.6 \mathrm{~m})$ is $0.39 \mathrm{~m} / \mathrm{s}$. At this point in the tidal cycle the water surface sits at $5.6 \mathrm{mCD}$ so there is approximately $25.6 \mathrm{~m}$ of water between the water surface and the tip of the HATT at top dead centre (TDC). Since a tidal velocity in excess of $1 \mathrm{~m} / \mathrm{s}$ is required for the operation of a HATT, the HATT may not be operational in these conditions (Black \& Veatch, 2005).

Considering the conditions at HWS +3 , the HATT would now sit in a lower water depth, such that there would be

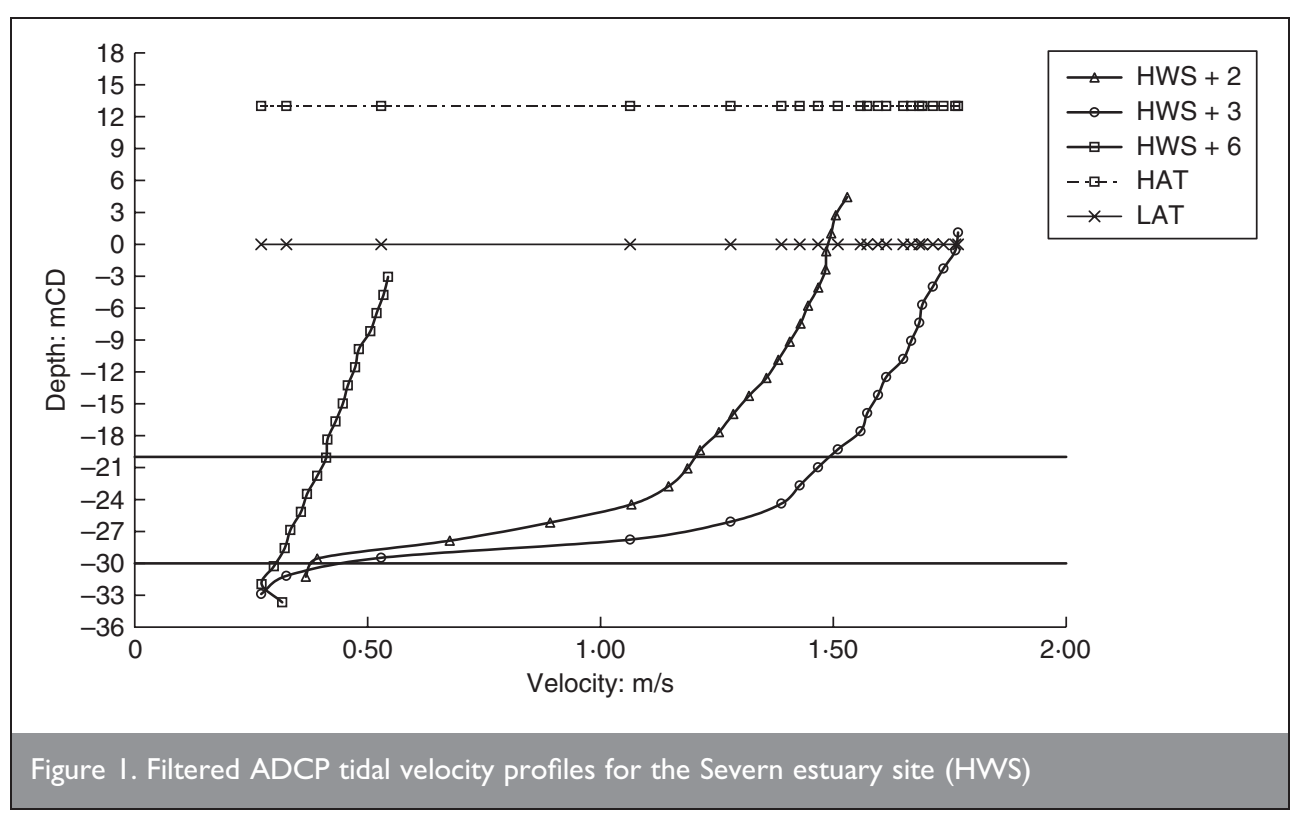




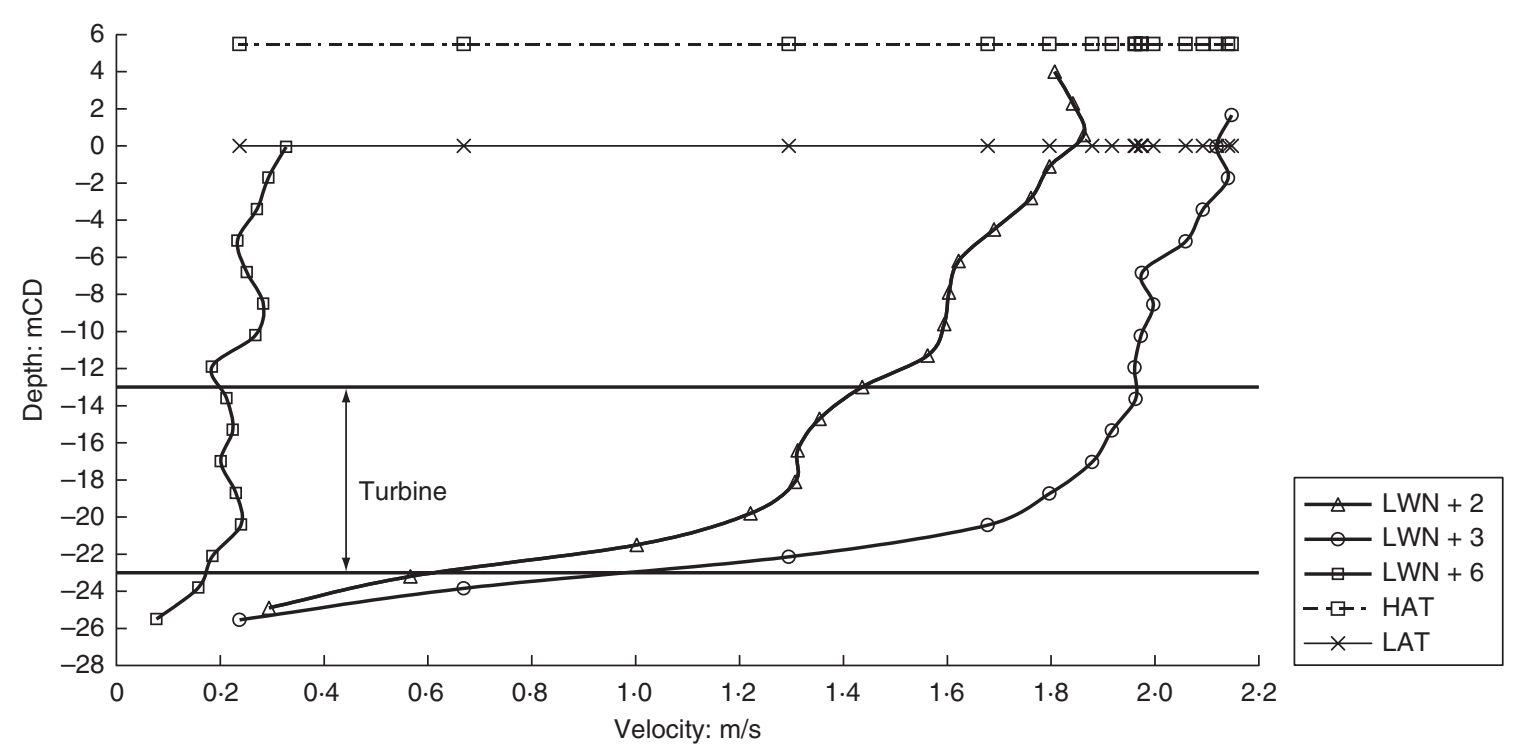

Figure 2. Filtered ADCP tidal velocity profiles for the Anglesey site (LWN)

approximately $21.5 \mathrm{~m}$ of water between the surface and the tip of the HATT at TDC. There is again a shear in the velocity from a peak of $1.56 \mathrm{~m} / \mathrm{s}$ at the uppermost section of the blades $(-20 \mathrm{mCD})$ to $0.45 \mathrm{~m} / \mathrm{s}$ at the lowermost section $(-30 \mathrm{mCD})$ giving a difference of $1 \cdot 11 \mathrm{~m} / \mathrm{s}$. At this tidal state, the HATT would be fully operational since the averaged velocity over the diameter is in excess of $1 \mathrm{~m} / \mathrm{s}$. However, there may be problems owing to the difference in pressure loadings across the blades, leading to asymmetric loading.

Figure 1 also shows the current velocities at HWS +6 which corresponds to slack water just before the tide is about to begin flooding. Here, the HATT sits in a water depth between $-17 \mathrm{mCD}$ and $-27 \mathrm{mCD}$ with corresponding velocities of $0.41 \mathrm{~m} / \mathrm{s}$ at the upper section and $0.32 \mathrm{~m} / \mathrm{s}$ at the lower section of the HATT. Thus, at this tidal state the turbine would not be operational. For local shipping this presents the worst-case scenario as this is the minimum freeboard likely to be seen, disregarding the effects of storm surges and waves.

On a more fundamental level it is clear from the ADCP data that the velocity profiles derived from the site reduce rapidly around $20 \mathrm{~m}$ below the surface and that the rate of decay is greater than profiles typically derived from the $1 / 7$ th power law, as will be discussed later. In shallower waters where the turbine diameter occupies a larger percentage of the water column this will have a more significant effect on power extraction or when its position is limited by shipping requirements and placed closer to the seabed.

The data for the Anglesey site are summarised in Figure 2. As with Figure 1 the current velocities are shown at three periods during the tidal range. Since the depth of water at this site is approximately equal to that in the Severn, the HATT would once again need to be positioned such that the axis of rotation of the turbine was $10 \mathrm{~m}$ from the seabed. For this site, the optimal operating conditions will be at LWN (low water neap) +3 when the HATT would sit in the water with a clearance of $14.5 \mathrm{~m}$ between the surface and the tip of the HATT at TDC. In this position there is a shear in the velocity from a peak of $1.95 \mathrm{~m} / \mathrm{s}$ at the uppermost section of the blades $(-13 \mathrm{mCD})$ to $1 \cdot 15 \mathrm{~m} / \mathrm{s}$ at the lowermost section $(-23 \mathrm{mCD})$, giving a difference of $0.8 \mathrm{~m} / \mathrm{s}$. At this tidal state, the HATT would be operational since the average velocity over the diameter is well in excess of $1 \mathrm{~m} / \mathrm{s}$. However, there may still be problems owing to the difference in pressure loadings across the blades leading to asymmetric loading, although this is less than that found with the Severn estuary data. Both the velocity and pressure variation over the turbine would be improved by siting the turbine higher in the water column.

At slack water $(\mathrm{LWN}+6)$, the HATT would sit lower in the water such that there would be approximately $13 \mathrm{~m}$ of water between the surface and the tip of the HATT at TDC with a reasonably constant velocity of $0.25 \mathrm{~m} / \mathrm{s}$ over the whole turbine section. Thus, again, at this tidal state the turbine would not be operational. As with the Severn site this presents the worst-case scenario, only now the freeboard at low slack water, during the neap tide, is actually less than the maximum vessel draft of $14.5 \mathrm{~m}$. This also does not include storm surges and waves. Hence the area would either have to have limited shipping access or the turbine diameter would need to be reduced so that it could sit lower in the water to provide the required freeboard. It should, however, be reiterated that this is during the worst-case scenario of slack water during a neap tide.

The shape of the profile in the Anglesey site does, however, develop into a much flatter area of peak velocity than that seen in the Severn site. This again reduces rapidly at around $20 \mathrm{~m}$ below the surface, but with a greater rate of decay than that found at the Severn site. Hence in shallower waters a greater area of the turbine will sit in the reduced velocities, so reducing the available power. The data from the Anglesey site also indicate that even during a neap tide the tidal velocity is sufficient to ensure an economic output (i.e. $>1 \mathrm{~m} / \mathrm{s}$ average) from a turbine over a reasonable percentage of the tidal cycle. 


\section{CFD MODELLING}

In the absence of a physical $10 \mathrm{~m}$ diameter turbine, CFD models at this scale were required to determine the performance of the turbine, in terms of torque, power and axial load. Previous work had determined the basic performance characteristics of a laboratory-scale HATT and a HATT under plug flow conditions where the tidal velocity was $3 \cdot 1 \mathrm{~m} / \mathrm{s}$ (6 knots) (Egarr et al, 2004; 0'Doherty et al, 2009a). A CFD model of a three bladed $0.5 \mathrm{~m}$ diameter HATT was validated through experimental measurements (O'Doherty et al, 2009b). This work is in agreement with the basic characteristics of the CFD models of other investigators, such as Bahaj et al. (2007) and Batten et al. (2008), providing confidence in the predictions. A further study showed that there was a scaling relationship between different sized turbines, ranging from 0.5 to $30 \mathrm{~m}$ diameter under plug flow conditions, providing confidence that the CFD model could be extended to a $10 \mathrm{~m}$ diameter turbine in a profiled flow (Mason-Jones, 2009). In all cases, the blades of the HATT used the Wortmann FX 63-137 profile as the basis of the design with the key geometric values being: length $3.8 \mathrm{~m}$, tip and root chord lengths 0.58 and $1.5 \mathrm{~m}$ respectively, and a twist of $34^{\circ}$. The blade design was originated using a mixture of an in-house beam element momentum program and CFD modelling.

Since the seabed at each of the sites was relatively flat, it was assumed that the bed could be modelled as flat (unpublished work has confirmed this assumption). The CFD domain was established as a rectangular channel $50 \mathrm{~m} \times 35 \mathrm{~m} \times 400 \mathrm{~m}$ representing the main tidal flow field, Figure 3. A depth of $35 \mathrm{~m}$ was chosen as this was the depth at the Severn estuary site. The length of $400 \mathrm{~m}$ was specified to ensure that the velocity-inlet and pressure-outlet were positioned 15 turbine diameters upstream and 25 turbine diameters downstream, respectively. The width of $50 \mathrm{~m}$ was specified to limit flow concentration effects between the turbine and the side walls (Egarr et al. 2004). To simulate an open water scenario zero friction was applied to the sides and surface boundaries of the channel. For the seabed the no-slip formulation was assumed. No interaction between surface waves and tidal current was considered.

The turbine was located in a cylindrical moving reference frame (MRF) with its axis of rotation $25 \mathrm{~m}$ below the surface boundary to ensure there was adequate clearance for any ships passing

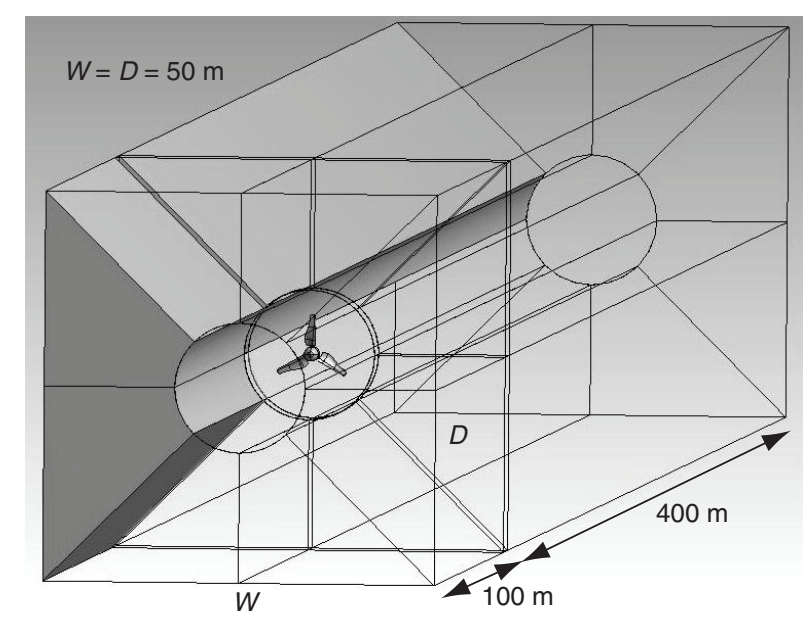

Figure 3. The CFD domain through. The turbine was located in a cylindrical MRF with its axis of rotation $25 \mathrm{~m}$ below the surface boundary to ensure there was adequate clearance for any ships passing through. The turbine volume was modelled using a cylindrical MRF volume with its axis of rotation through the centre of the hub to allow the angular velocity of the turbine $(\omega)$ to be varied. The MRF volume was subtracted from the rectangular channel representing the remainder of the model.

Although it has already been noted that the HATT would have limited operation both in the Severn estuary and the Anglesey Skerries, owing to the low tidal velocities, it was decided to determine the effects of the velocity profile on the performance characteristics of the turbine. To ensure all other variables were excluded, the magnitudes of the fastest velocity profile at each site were chosen and scaled to give a peak velocity of $3.1 \mathrm{~m} / \mathrm{s}$ since it has been suggested that if tidal turbines are to be commercially viable, they must operate in waters with a peak velocity of at least $3 \cdot 1 \mathrm{~m} / \mathrm{s}$ (6 knots) (Black \&t Veatch, 2005). For the Severn estuary site, this corresponded to HWS +3 (Figure 4) and for the Anglesey site the fastest velocity profile was observed at $\mathrm{LWN}+3$. Since the depth at these two respective time points at the different sites was also different, it was decided to harmonise the models to a depth of $35 \mathrm{~m}$ which was the natural depth of the Severn estuary. Since the site in the Anglesey Skerries was only $32 \mathrm{~m}$ deep, the velocity profile was also 'stretched' to cover $35 \mathrm{~m}$ (Figure 5). In addition, a reference model which included an idealised plug flow with the inlet tidal velocity in the range $1-3 \cdot 1 \mathrm{~m} / \mathrm{s}$ was created.

Since no reliable turbulence measurements were made at any of the sites, the turbulence intensity was based on the hydraulic diameter method where the characteristic length was based on the blade chord length. This resulted in a turbulence intensity of 5\% being applied at both the velocity-inlet and pressure-outlet. This meant that three models, all based on the same domain, but with different inlet tidal velocity profiles could be compared. It is, however, acknowledged that in reality the level of turbulence will vary down the length of water column. At the water's surface the interaction of waves will result in increased levels of turbulence and the levels near the seabed will be dependent on the surface topography upstream of the site. Since the turbine's position in the water column is away from both surfaces it is felt that this is reasonable for this work.

As with the previous study, the 'Reynolds averaged Navier-Stokes' (RANS) equations were used to relate the Reynolds stresses to the mean velocity gradients and the Reynolds stress model (RSM) was used as the viscous model.

The meshed model included $\sim 1$ million cells around the turbine and a further 90000 cells for the remaining flow field. The cell count was controlled by the number of cells initially generated while meshing the faces of each turbine blade and hub. A finer mesh density was placed towards the tip of the blade within the last $1 / 3$ of the blade length. The upstream and downstream faces were meshed with increasing mesh densities.

At each converged steady-state solution, a user-defined function (UDF) was used to extract the torque $(\boldsymbol{T})$ and axial 


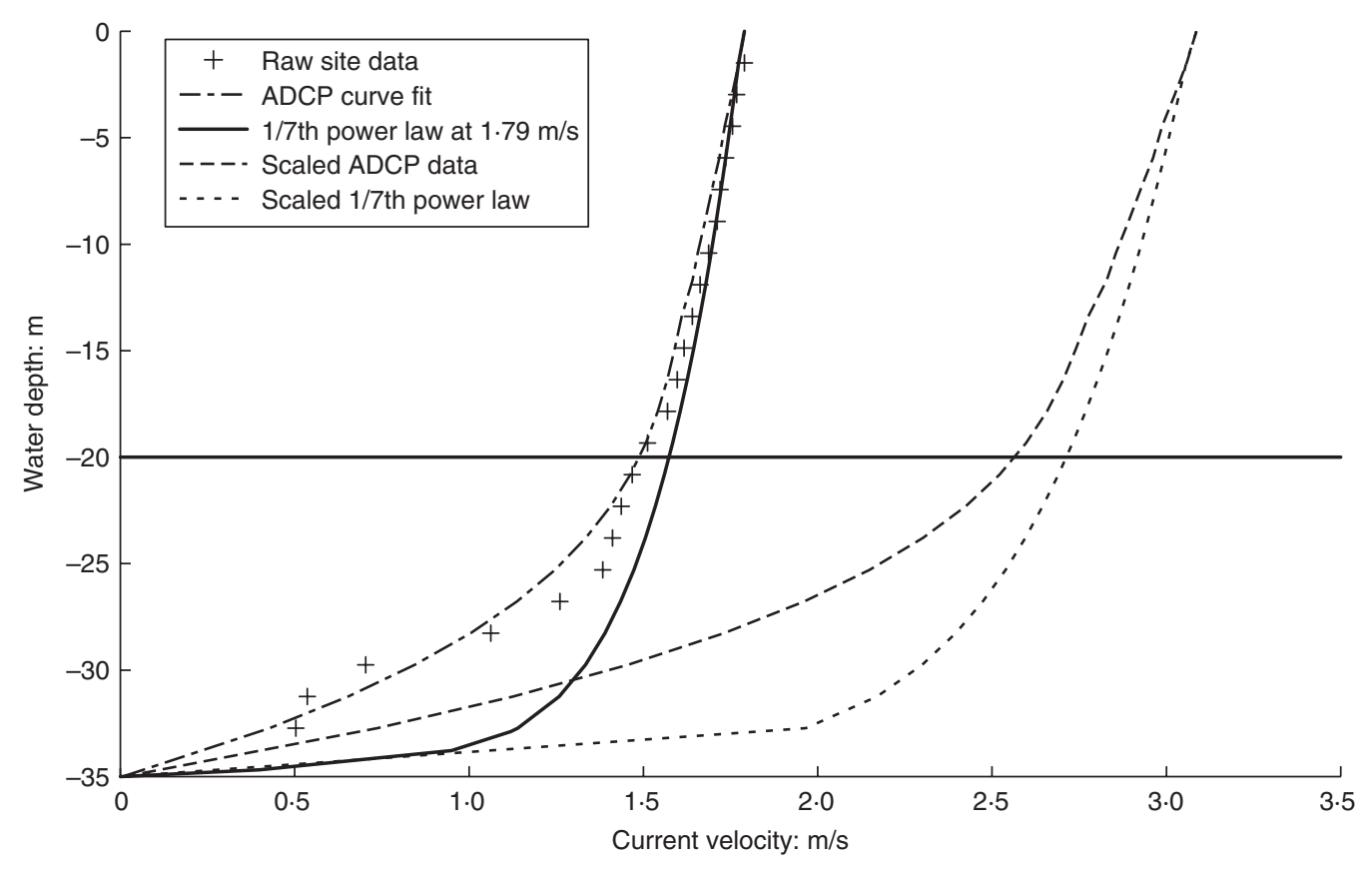

Figure 4. ADCP and I/7th power law velocity profiles for the Severn estuary site

thrust force $\left(\boldsymbol{F}_{\mathrm{t}}\right)$. The peak torque $\left(\boldsymbol{T}_{\max }\right)$ was calculated at every converged solution by integrating and resolving forces at each cell face by way of the UDF. The product of $\mathbf{T} \boldsymbol{\omega}(\mathrm{W})$ was then used to calculate the peak power $P_{\mathrm{p}}(\mathrm{W})$. Finally, the power coefficient for the $10 \mathrm{~m}$ swept area was calculated using Equation 2.

\begin{tabular}{|l|l|}
\hline 2 & $C_{\mathrm{p}}=\frac{\boldsymbol{T} \boldsymbol{\omega}}{0 \cdot 5 \rho A \boldsymbol{V}^{3}}$ \\
\hline
\end{tabular}

From the angular velocity $(\boldsymbol{\omega})$ sweeps, run over a range of blade pitch angles, a series of power curves were developed. The power available over a given cross-sectional area for a given tidal flow can be calculated using Equation 3. A limiting factor to $C_{\mathrm{p}}$ is given by the Betz law (derived by A. Betz in 1920) where only a theoretical maximum of $59 \cdot 3 \%$ of the available energy can be physically extracted (Betz, 1966).

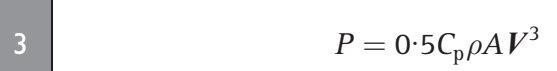

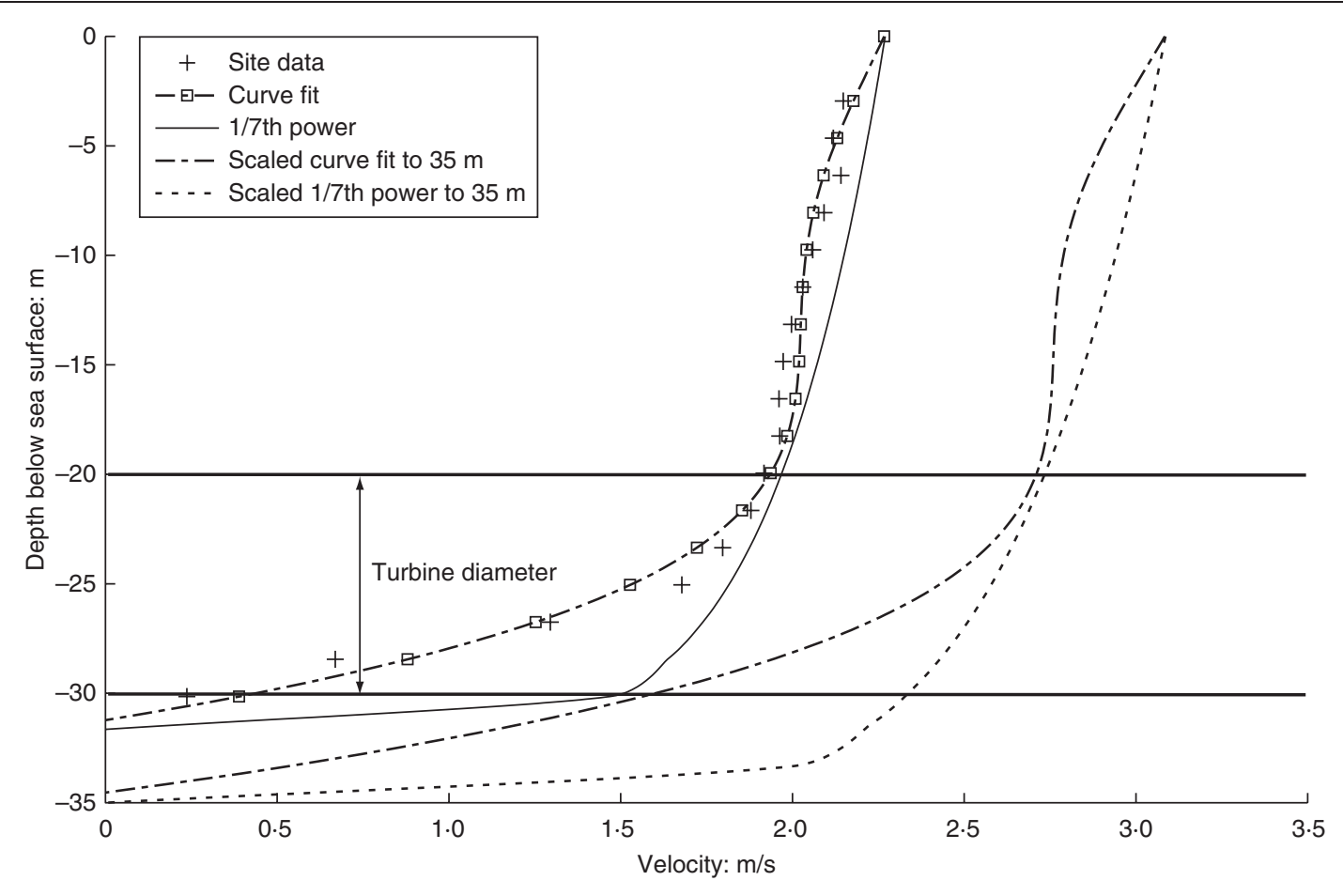




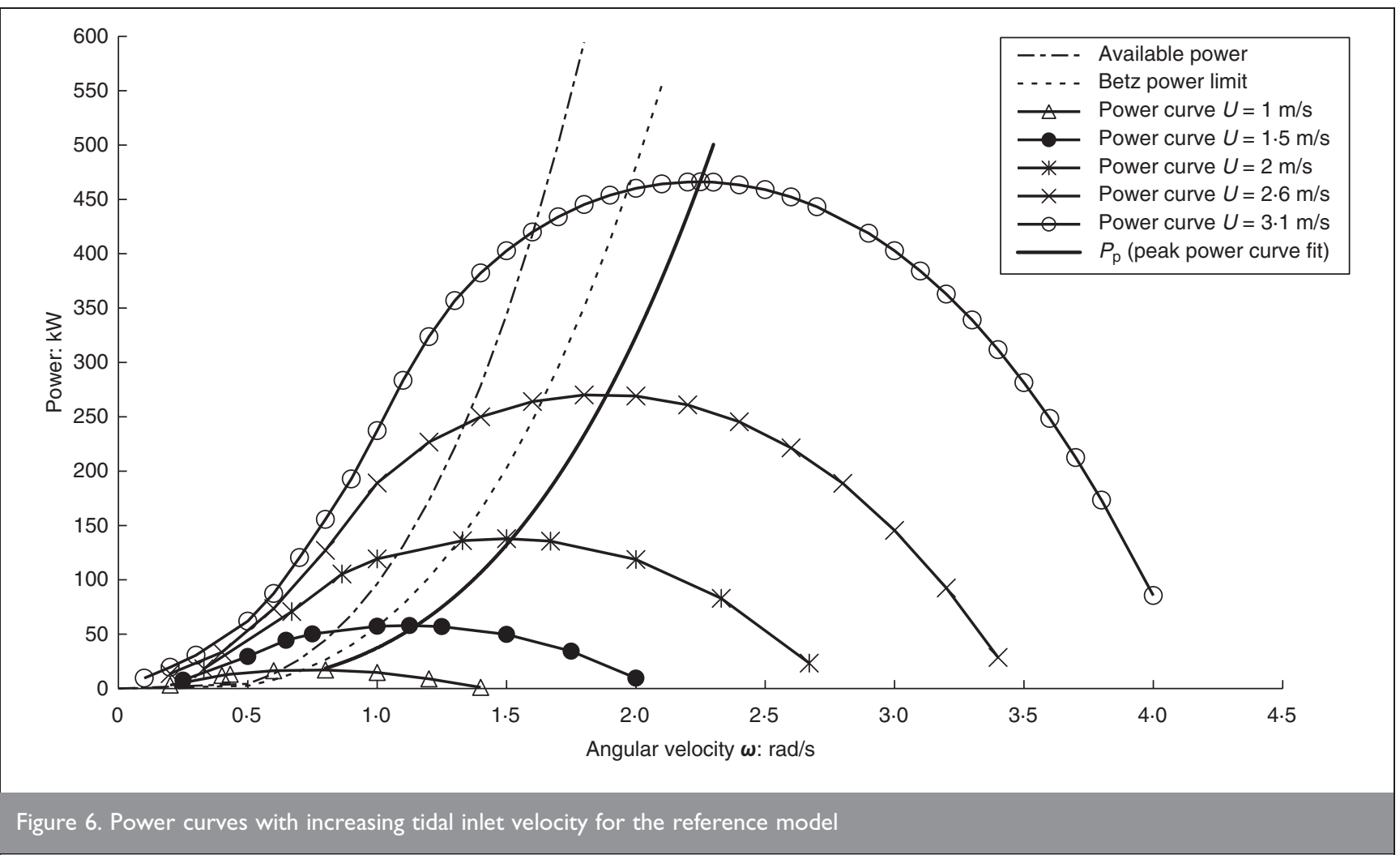

\section{I. Turbine power using CFD reference model}

The cubic power in the velocity component makes the power output of the turbine highly dependent on the tidal velocity throughout the tidal range. Figure 6 shows a series of power curves generated for five tidal velocities in the range 1-3.2 m/s using the reference CFD model. The available power, theoretical extraction (Betz) limit and peak power $\left(P_{\mathrm{p}}\right)$ extracted by the turbine by way of equation fits are also given.

The performance characteristics of the $10 \mathrm{~m}$ diameter HATT were established for idealised plug flow conditions. $C_{p}$ was calculated using Equation 2 using the torque and angular velocity at peak power. A maximum $C_{\mathrm{p}}$ of $40 \%$ occurred at $2 \cdot 25 \mathrm{rad} / \mathrm{s}(22 \mathrm{rpm})$ and a tip speed ratio (TSR) of $3 \cdot 6$. The peak torque occurred at $\boldsymbol{\omega}=1.3 \mathrm{rad} / \mathrm{s}(12 \mathrm{rpm})$ with a TSR of $2 \cdot 2$. The HATT starts to freewheel at $\boldsymbol{\omega}=4 \cdot 13 \mathrm{rad} / \mathrm{s}(39 \mathrm{rpm})$ and a TSR of approximately $6 \cdot 7$.

\subsection{CFD model of the sites}

The data collected from the Severn estuary site were taken during a spring tide while the data from the Anglesey site were taken during a neap tide. According to the Sustainable Development Commission, 'there is approximately eight times more tidal stream power during spring tides than at neaps' (Carbon Trust, 2005). Hence this implies, from Equation 2, that the peak velocity for the Anglesey site, for a spring tide, would be twice that at neap tide (i.e. up to $4 \mathrm{~m} / \mathrm{s}$ ). This assumes that the velocity profile during a spring tide is the same as the profile found from the data collected during a neap tide. This is only an approximation but gives an indication of the power generated during a spring tide. Ideally further data would need to be collected from the Anglesey site during a spring tide to verify this.

For the maximum power extraction the optimum position for the turbine is towards the water surface where the tidal velocity is highest. However, as previously stated, this is prohibitive owing to restrictions imposed by local shipping requirements. Although this is a site-specific restriction it may well apply to many locations where the siting of a HATT is suitable. For the CFD models the rotation axis of the turbine was positioned $25 \mathrm{~m}$ below the water surface, allowing adequate clearance between the turbine blades at TDC and the maximum vessel draft. However, this places the turbine in a high shear region of flow which considerably reduces the power density. Figure 4 and Figure 5 show a polynomial curve fit to the filtered ADCP data for each site and the rescaled curve for a peak tidal flow of $3 \cdot 1 \mathrm{~m} / \mathrm{s}$. In all cases the shear of the curve through the water column was not altered with increased velocity. Moreover, for comparison with peak power the 1/7th power law is also plotted for each case. It is clear that the shear towards the seabed is far steeper than that represented by the power law typically as evident in Figures 5 and 6 . It can also clearly be seen that while the Anglesey site profile provides a much shallower gradient in the first $20 \mathrm{~m}$ than that of the Severn estuary profile, the gradient in the region suggested for the turbine, that is between 20 and $30 \mathrm{~m}$ depth, is much greater for the Anglesey site $(0 \cdot 125 \mathrm{~s})$ than that of the Severn estuary site $(0 \cdot 075 \mathrm{~s})$. Hence the shear across the turbine will be much higher for the Anglesey site, with the potential to cause greater 'wear and tear', damage and maintenance costs over the life of the turbine. However, clearly from Equation 2 the average velocity 'seen' by the turbine in the Anglesey site is nearly twice that of the Severn estuary site, which would result in the maximum potential power output to be $\sim 8$ times that of the Severn estuary site. To study the implications of high shear, the results from idealised plug flow and profiled flows were compared by looking at the performance of the HATT under both conditions.

With the idealised plug flow of $3 \cdot 1 \mathrm{~m} / \mathrm{s}$ the CFD model gave peak power of $466 \mathrm{~kW}$ (Figure 7). However, with the 


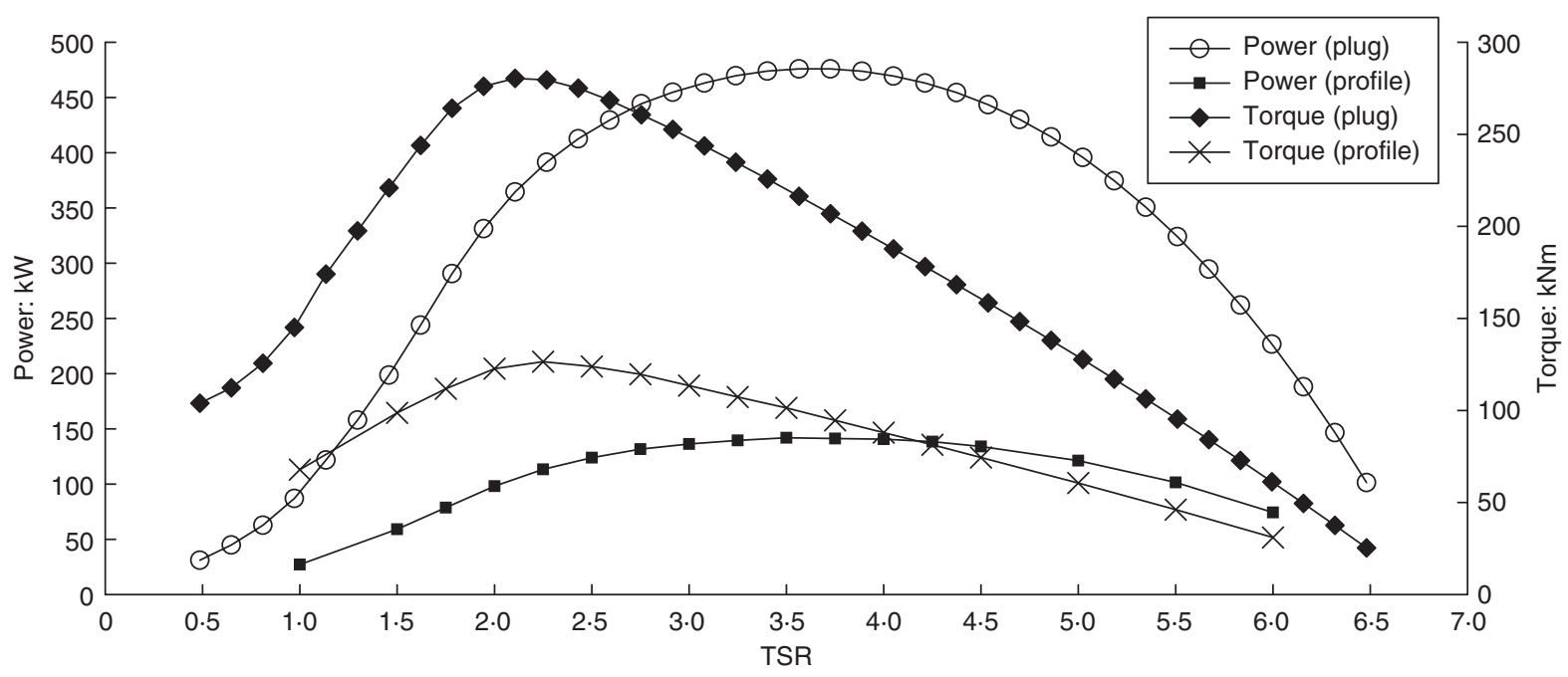

(a)

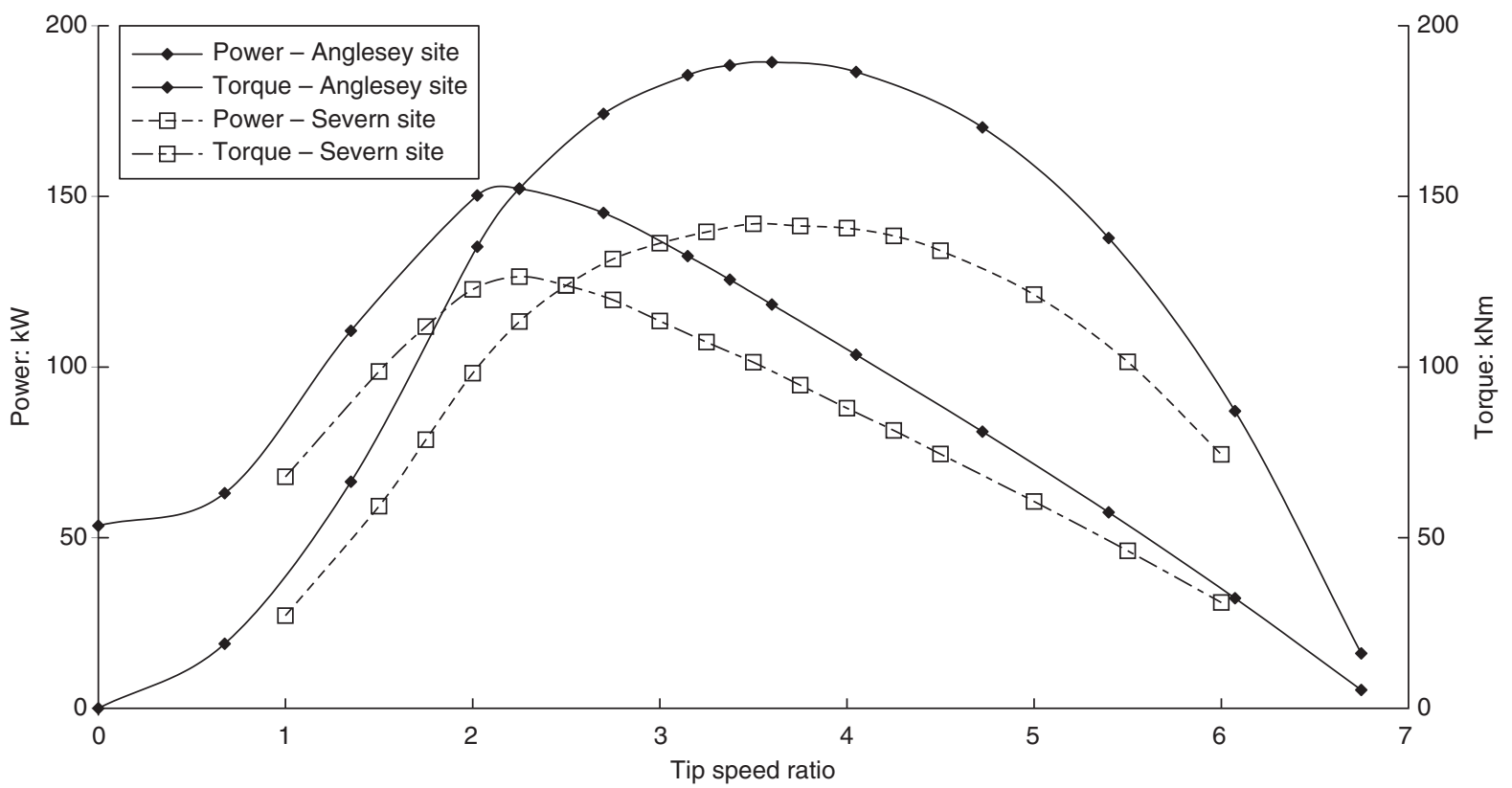

(b)

Figure 7. The torque and power curves for the three models with a peak velocity of $3.1 \mathrm{~m} / \mathrm{s}$

introduction of the profiled velocity flow, derived from the $\mathrm{ADCP}$ site data, the power density at $25 \mathrm{~m}$ below the water surface is considerably reduced and thus the torque and power extracted by the HATT are reduced. For the Severn estuary site, the peak power was $142 \mathrm{~kW}$, while the power for the Anglesey site was $\sim 185 \mathrm{~kW}$ - that is, only 30 and $40 \%$ of the peak plug flow power respectively.

Considering the whole tidal cycle and taking the 'cut-in' velocity to be $1 \mathrm{~m} / \mathrm{s}$ it can be estimated that a peak power output for the idealised plug flow would translate into approximately $1.5 \mathrm{GWh} /$ year. This would compare with $0.55-0.66 \mathrm{GWh} /$ year when positioned in the flow regimes discussed in this paper.

In scaling the velocity profile the rate of change in velocity through the depth was unchanged for the Severn estuary site and marginally changed for the Anglesey site. However, assuming the profile is basically the same, no matter what the tidal velocity is, is not fully justifiable and a change in shape should be expected. This phenomenon is illustrated in both Figure 1 and Figure 2. Using the data from the Severn estuary to illustrate the point, it can be seen that as the velocity increases to the maximum velocity at HSW $+3 \mathrm{~h}$, the high shear rate moves to a greater depth with the highest shear starting at around $26 \mathrm{~m}$ below the water surface. The changed profile shape can be likened to that used to describe velocity profiles in the laminar and turbulent boundary layer regions (Douglas et al., 2005). However, the magnitude of this change needs further investigation before the assumption can be dismissed.

When the velocity profiles for the two sites have been scaled to the same peak velocity and water depth, the power and torque curves can be compared to each other to assess the effects of the profile shape. It should be clarified that the Anglesey site velocities are much higher than those of the Severn estuary site 


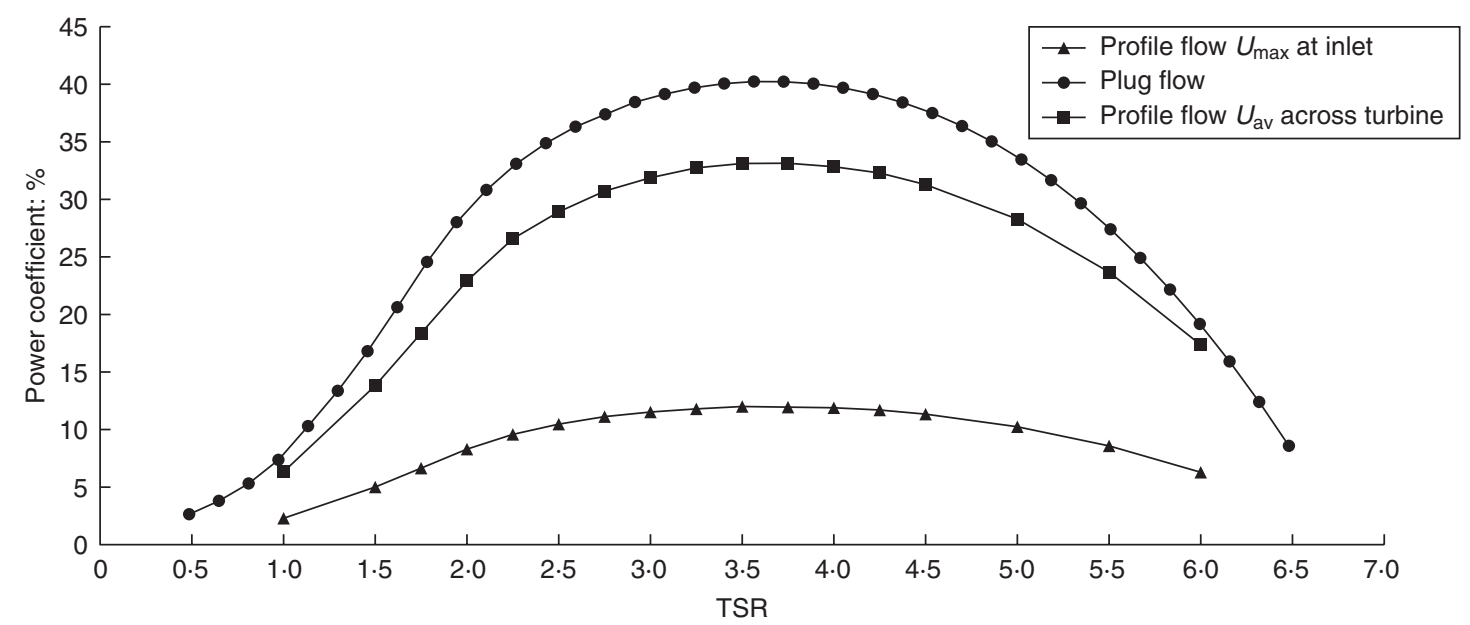

Figure 8. Reduction in power coefficient using profiled velocity Severn estuary site data

so would automatically produce higher values. However, with the scaling, Figure 7 clearly shows that the very shape of the Anglesey site profile provides $\sim 30 \%$ more power than that of the Severn estuary site. The turbine at either site has a peak power at a TSR of $\sim 3 \cdot 6$, with the peak torques occurring at a TSR of $\sim 2 \cdot 2$. Interestingly the average velocity over the turbines only varies by a small amount with the average velocity for the Severn site being $2.20 \mathrm{~m} / \mathrm{s}$ and that for the Anglesey site being $2 \cdot 23 \mathrm{~m} / \mathrm{s}$. Hence the distribution of the velocity over the swept area is as critical as the average value itself.

From the reference CFD domain results the power coefficient of the turbine was shown to be circa $41 \%$. This would agree with other references which quote HATTs to operate with a nominal $C_{\mathrm{p}}$ of between 40\% (Clarke et al., 2006) and 45\% (Carbon Trust, 2005). Typically, $C_{\mathrm{p}}$ is calculated from the available resource upstream of the turbine and if the idealised plug flow conditions are assumed, $C_{\mathrm{p}}$ is unambiguous since the velocity is constant throughout the water column with slight attenuation towards the seabed from near wall boundary conditions. However, when considering a profiled flow the choice of upstream tidal velocity has a direct effect on the value of the calculated power coefficient. If for example the maximum upstream velocity of $3.1 \mathrm{~m} / \mathrm{s}$ is taken then the available energy density is calculated from the velocity $1 \mathrm{~m}$ below the water surface and the $C_{\mathrm{p}}$ value is only $12 \%$. This provides a misleading performance estimate of the turbine since it does not occupy the higher portion of the water column. If the upstream velocity in line with the axis of rotation - that is, $2.55 \mathrm{~m} / \mathrm{s}$ - is taken, the $C_{\mathrm{p}}$ value would be $22 \%$, while if the average velocity across the turbine diameter that is, $2 \cdot 20 \mathrm{~m} / \mathrm{s}$ - is used to calculate the turbine's performance, the $C_{\mathrm{p}}$ value is $34 \%$ (Figure 8). This then shows the large drop-off in power extracted owing to the lower average velocity across the HATT diameter at that depth. This illustrates the significant effect the upstream velocity has on the performance of the turbine and the need to clarify the operational boundaries to which the HATT is matched, and how its performance is monitored during operation.

One way to increase the $C_{\mathrm{p}}$ value would be to place the turbine at a higher position in the water column, although the shipping requirements discussed earlier would have to be ignored.
Figure 9 shows the power, normalised to the plug flow data, for the Severn estuary site with the HATT positioned at various depths. Since the CFD model of the HATT occupies a cylindrical MRF that slightly extends its diameter, gaps are left between the water and seabed boundary. In reality if the turbine were positioned at a depth below $5 \mathrm{~m}$ in the water column, the turbine blades would start to break the water surface, meaning the turbine would be operating in partial submersion. Below $30 \mathrm{~m}$ the turbine would foul with the seabed.

It is also clear from Figure 9 that power density calculations based on the tidal velocity just below the water surface are misleading. For example, for the Severn estuary site the portion of the velocity profile $10 \mathrm{~m}$ below the surface is optimum. If the rotation centre of the turbine was positioned at this depth the normalised power extracted by the HATT would be reduced by 0.65 for the Severn estuary site, compared with the idealised plug flow conditions.

The variation of axial load with tip speed ratio can be seen in Figure 10. Given that the average velocities over the turbines for the two sites are very similar, the axial load curves shown are representative of both sites since the axial load is proportional to the square of the mean tidal velocity, as shown by Equation 4

\begin{tabular}{|l|l|}
\hline 4 & $\boldsymbol{F}_{\mathrm{t}}=C_{\mathrm{T}} 0 \cdot 5 \rho A \boldsymbol{V}^{2}$ \\
\hline
\end{tabular}

The curve for the plug flow indicates the maximum possible load, $\sim 380 \mathrm{kN}$, that would result from a flow of 6 knots, or $3 \cdot 1 \mathrm{~m} / \mathrm{s}$. However, since the turbines would 'sit' in a lower velocity than that of the near surface velocity the loads are much lower at $\sim 205 \mathrm{kN}$. The figure also shows the result for the $1 / 7$ th power curve fit at $\sim 260 \mathrm{kN}$. What is not taken into account here is that the actual loads on the blades would be highly asymmetric at the $25 \mathrm{~m}$ depth owing to the profiled flow. This could well be more of a problem than a higher, but uniform, load. The Anglesey site profile is flatter higher up the water column than the Severn estuary site profile, so would be a better site from this perspective. It can also be seen from Figure 10 that the axial load continues to increase with the maximum occurring at the freewheeling velocity. However, this 


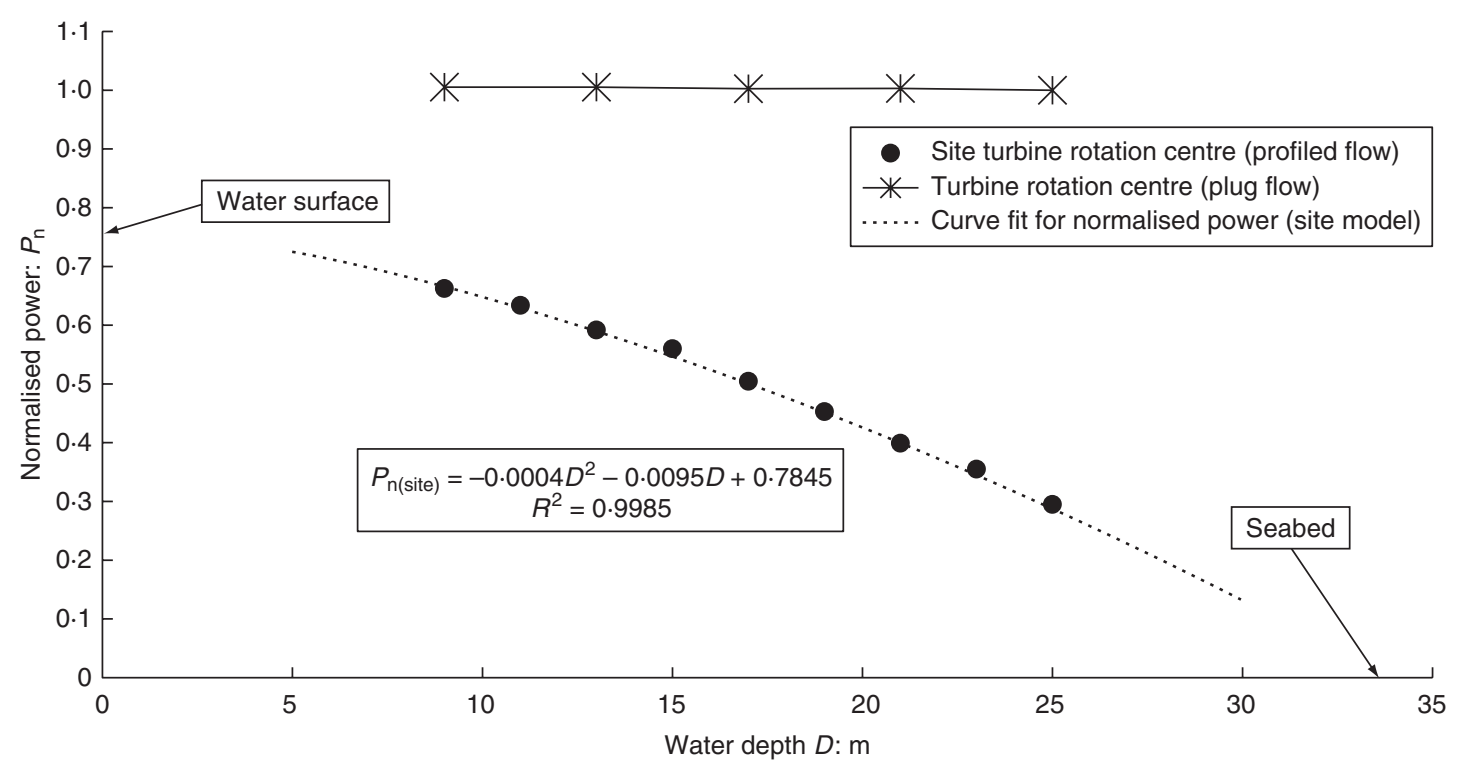

Figure 9. Normalised power attenuation through water column for Severn estuary site CFD model with plug

operating condition should, and would, be avoided for two reasons, the first being that the load is highest and second since the torque becomes zero at the freewheeling velocity the power extracted would also become zero. The curves also indicate that at $P_{\mathrm{p}}$ there would be a reduction of the axial load to $\sim 88 \%$ of the freewheeling load. The load would drop to $\sim 75 \%$ of the freewheeling load at a TSR of $2 \cdot 4$ with the power dropping to 85\% of $P_{\mathrm{p}}$.

\section{OVERALL DISCUSSION}

The hydrographic and hydrodynamic high-resolution Swath bathymetric survey and the vessel-mounted ADCP surveys produced excellent data to investigate the characteristics of a HATT positioned in two sites off the Welsh coast. The bathymetric surveys provided accurate and detailed bathymetry of the sites, thus allowing the identification of potential locations to site HATTs with regard to surface topography. This was complemented by ADCP transect surveys which produced detailed current velocities through the water column and the overall flow regimes. Flow velocities were measured in order to assess whether the currents possess the necessary strength to power the HATT and to examine the velocity profile through the water column, over a tidal cycle. The maximum peak velocities for both sites were towards the water surface, with the Anglesey site providing a much higher velocity. The tidal velocity for economic energy extraction is typically quoted to be between $2 \mathrm{~m} / \mathrm{s}$ and $3 \mathrm{~m} / \mathrm{s}$ at mean spring tide (Carbon Trust, 2005), therefore for the location the velocity at the Severn estuary site was considered to be too low for economic deployment of tidal stream turbines. The Anglesey site would, however, meet the economic requirements even at neap tide, particularly if the turbine was positioned at $20 \mathrm{~m}$ depth, or higher. Furthermore,

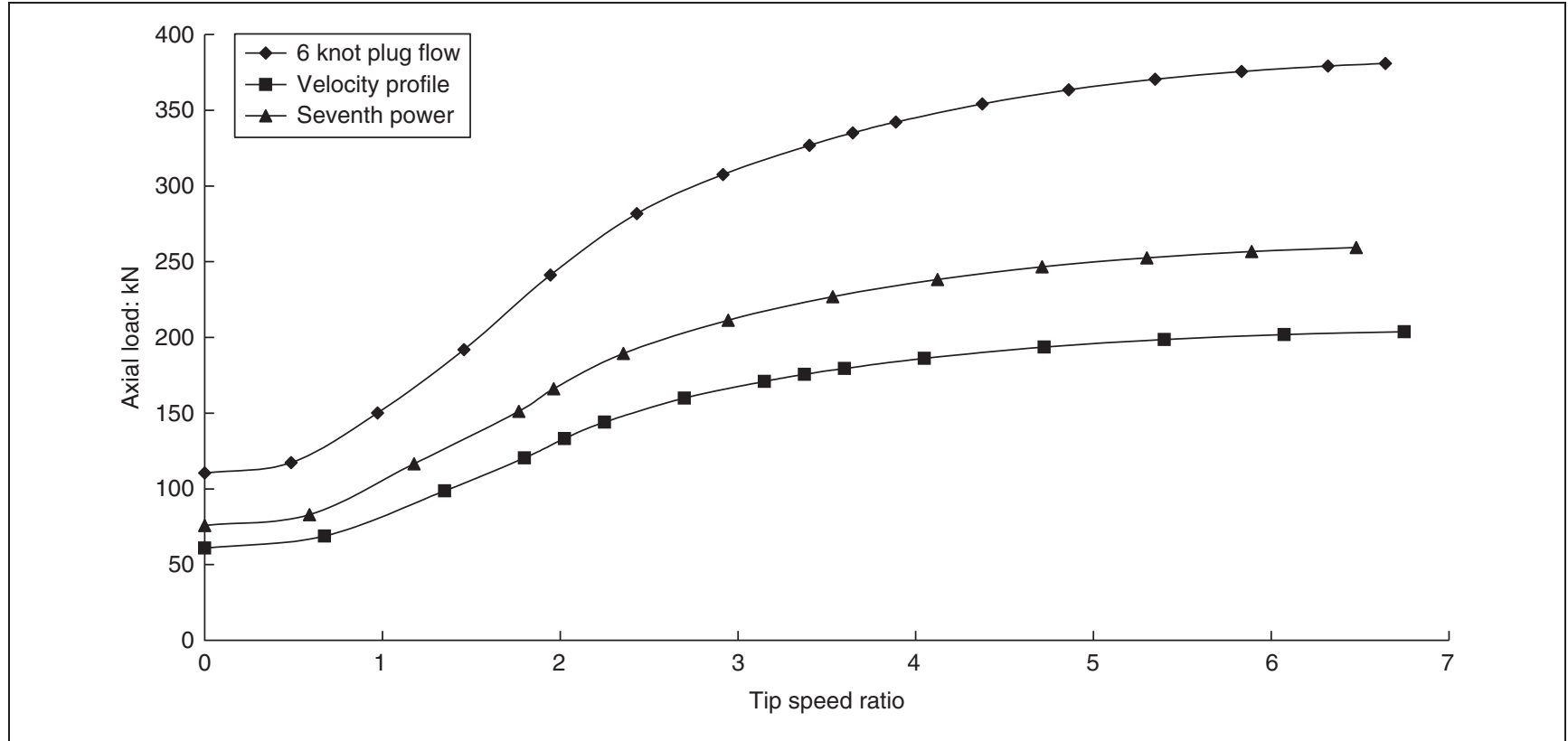


for the Severn estuary site the turbine must be located around $25 \mathrm{~m}$ below the surface to avoid shipping and thus would never see the peak value $1.8 \mathrm{~m} / \mathrm{s}$. Alternatively, arrays of smaller turbines may be possible, but would need to be evaluated. Although it is unlikely that this location would be suitable for energy extraction, the study has shown that local velocity profiles may vary considerably from that typically calculated using the 1/7th power law. In shallower waters where the turbine diameter occupies a larger percentage of the water column, this will have a significant effect on power extraction or as in this case when its position is limited by shipping requirements and placed closer to the seabed.

In order to compare the effects of the shape of the velocity profiles, the profiles were rescaled. The scaling was undertaken so that the peak tidal velocities met the upper range of the economically viable tidal current - that is, 6 knots or $3 \cdot 1 \mathrm{~m} / \mathrm{s}$. The performance characteristics were then used to develop a qualitative understanding of how they change as parameters vary with resource attenuation through the water column, specifically within shallower depths less than $40 \mathrm{~m}$. It was found that the peak power extracted was approximately $466 \mathrm{~kW}$ for a $3 \cdot 1 \mathrm{~m} / \mathrm{s}$ plug flow. However, with the rescaled profile flow this value reduced to $142 \mathrm{~kW}$ for the Severn estuary site and $185 \mathrm{~kW}$ for the Anglesey site - that is, up to 70\% reduction in power extraction from the sites when compared to near surface calculations. Since the mean tidal velocities over the turbines are very similar, the power output should be virtually the same. However, the shape of the velocity is also clearly critical since the power from the Anglesey site was 30\% higher than that of the Severn estuary site. So while the mean velocities may be similar, the Anglesey site offers a greater velocity over part of the turbine's swept area, providing a small increase in the torque generated, hence an increase in the power developed.

For a true representation of turbine performance the tidal velocity should be monitored between 2 and 5 turbine diameters upstream of the HATT and at the depth of its rotation axis. The $C_{\mathrm{p}}$ of the turbine with plug flow conditions shows that the value is $\sim 40 \%$. However, since the turbine was positioned in the profiled flows this value could vary depending on the upstream velocity definition. For example if the Severn estuary site is considered, by using the peak upstream near surface tidal velocity $(3.1 \mathrm{~m} / \mathrm{s})$ and using Equation 2 , the $C_{p}$ was reduced to $12 \%$. However, if the average flow velocity across the turbine diameter is used, the $C_{\mathrm{p}}$ was calculated as $34 \%$. This then clearly illustrates the need to clarify the operational boundaries to which the HATT is matched and how its performance is monitored during operation.

What must also be clearly considered along with the power developed is that of the axial load developed. While this paper does not evaluate the stresses developed within the turbine structure it would be clear that the peak axial loads on the turbines are best avoided owing to the stresses that are likely developed. Also if the turbine was mounted on a shaft secured to the seabed the moment developed would obviously be at its greatest. Hence allowing the turbine to approach freewheeling speeds would be unadvisable. Since the mean load is related to the square of the mean tidal velocity ('seen' by the turbine), the mean loads were very similar at both sites (within 3\% of each other). What could be a more significant issue is the fact that the variation of the velocity over the water column would clearly result in an asymmetric loading on the turbines.

\section{CONCLUSIONS}

Two sites off the Welsh coast, in the Severn estuary and off Anglesey, were considered using ADCP and Swath bathymetry data, for potential deployment of tidal stream turbines. Using CFD analysis a $10 \mathrm{~m}$ diameter, three-bladed turbine was assessed against a plug flow and two profiled flows.

The velocity at the Severn estuary site is unlikely to provide a suitable level of power to be viable. The Anglesey site, however, would meet the economically viable velocity of $2-3 \mathrm{~m} / \mathrm{s}$.

Owing to the velocity profile through the water column the power developed would be significantly less; that is, $30-40 \%$ of that assumed if the near surface velocity is considered (466 kW at $3 \cdot 1 \mathrm{~m} / \mathrm{s}$ plug flow).

The axial load developed on the turbine peaks at the freewheeling velocity. At $P_{\max }$ this load drops to $\sim 88 \%$ reducing to $75 \%$ when the power reduces by $15 \%$.

Owing to the severity of the velocity profile through the water column the axial load on the turbine will be asymmetrical.

\section{ACKNOWLEDGEMENT}

This research was funded by a European Regional Development Fund grant through the Welsh Assembly government and the Knowledge Exploitation Fund.

\section{REFERENCES}

Bahaj AS, Batten WMJ and McCann G (2007) Experimental verification of numerical predictions for the hydrodynamic performance of horizontal axis marine current turbines. Renewable Energy 32(15): 2479-2490.

Batten WMJ, Bahaj AS, Molland AF and Chaplin JR (2008) The prediction of the hydrodynamic performance of marine current turbines. Renewable Energy 33(5): 1085-1096.

Betz A (1966) Introduction to the Theory of Flow Mechanics (translated by DG Randall). Pergamon Press, Oxford.

Black \& Veatch (2005) Phase II UK Tidal Stream Energy Resource Assessment. Carbon Trust, Witney.

Carbon Trust, United Kingdom Wave and Tidal Energy Study (2005) Variability of UK Marine Resources. Carbon Trust, Witney, Final report.

Clarke JA, Connor G, Grant AD and Johnstone CM (2006) Regulating the output characteristics of tidal current power stations to facilitate better base load matching over the lunar cycle. Renewable Energy 31(2): 173-180.

Douglas CA, Harrison GP and Chick JP (2007) Life cycle assessment of the Seagen marine current turbine. Proceedings of IMechE, Part M: Journal of Engineering for the Maritime Environment 222(1): 1-12.

Douglas JF, Gasiorek JM and Swaffield JA (2005) Fluid Mechanics. Pearson, Harlow.

DTI (Department for Trade and Industry) (2006) SEAFLOW Marine Current Turbines Summary Report. DTI, London, Report PS244.

Egarr DA, O’Doherty T, Morris S and Ayre RG (2004) Feasibility study using computational fluid dynamics for the use of a turbine for extracting energy from the tide. Proceedings of 
the 15th Australasian Fluid Mechanics Conference, Sydney. CDROM, paper AFMC00024.

EMEC (European Marine Energy Centre) (2008) See http:// www.emec. org.uk/tidal_developers.asp (accessed 01/10/ 2008).

Fujita Research (2000) Wave and Tidal Power. See www.fujitaresearch.com/reports/tidalpower.html (accessed 01/03/2009)

Green Party (2009) Green Party welcomes news that Strangford seals unaffected by tidal turbine. See http://www. downgreens.com/?p=647 (accessed 01/07/2009).

Kostaschuk R, Best J, Villard P, Peakall J and Franklin M (2005) Measuring flow velocity and sediment transport with an acoustic Doppler current profiler. Geomorphology 68(1-2): 25-37.

Marine Current Turbines (2009) See http:// www.marineturbines.com/18/projects/20/the_skerries/ (accessed 01/05/2009).

Mason-Jones A (2009) Performance Assessment of a Horizontal Axis Tidal Turbine in a High Velocity Shear Environment. $\mathrm{PhD}$ thesis, Cardiff University, submitted.

0'Doherty T, Egarr DA, Mason-Jones A and O'Doherty DM (2009a) An assessment of axial loading on a 5 turbine array. Proceedings of the Institution of Civil Engineers, Energy 162(2): 161-181.

0'Doherty T, Mason-Jones A, O'Doherty DM et al. (2009b) Experimental and computational analysis of a model horizontal axis tidal turbine. EWTEC, Uppsala, Sweden, pp. 833-834.

Savage G (2009) The environmental monitoring programme for the SeaGen tidal turbine, Strangford Narrows, Northeren Ireland. See http://www.rse.org.uk/international/RSETaiwan\%20tidal\%20energy\%20slides/RSE-Taiwan/ ROYSOCEDINPRES240209.ppt (accessed 01/07/2009).

Soares C (2002) Tidal power: the next wave of electricity. Pollution Engineering. See www.pollutionengineering.com (accessed 01/03/2009).

Sustainable Development Commission (2007a) Tidal technologies research report 2; tidal power in the UK. See http:// www.sd-commission.org.uk/pages/tidal-power.html (accessed 01/03/2009).

Sustainable Development Commission (2007b) Turning the tide, tidal power in the UK. See http://www.sd-

commission.org.uk/publications.php?id=6072007 (accessed 01/03/2009).

\section{What do you think?}

To discuss this paper, please email up to 500 words to the editor at journals@ice.org.uk. Your contribution will be forwarded to the author(s) for a reply and, if considered appropriate by the editorial panel, will be published as a discussion in a future issue of the journal.

Proceedings journals rely entirely on contributions sent in by civil engineering professionals, academics and students. Papers should be 2000-5000 words long (briefing papers should be 1000-2000 words long), with adequate illustrations and references. You can submit your paper online via www.icevirtuallibrary.com/content/journals, where you will also find detailed author guidelines. 